\title{
Minyak Nilam sebagai Biofungisida untuk Pengendalian Penyakit Antraknosa Cabai
}

\author{
Patchouli Oil as Biofungicide to Control \\ Anthracnose Disease on Chilies \\ Desni Roha Miriam Sakerebau, Bonny Poernomo Wahyu Soekarno* \\ Institut Pertanian Bogor, Bogor 16680
}

\begin{abstract}
ABSTRAK
Antraknosa merupakan salah satu penyebab rendahnya produktivitas cabai di Indonesia yang disebabkan oleh Colletotrichum capsici. Penelitian ini dilakukan untuk menguji potensi minyak nilam dalam menghambat perkembangan penyakit antraknosa pada cabai. Uji in vitro dilakukan dengan cara isolat $C$. capsici ditumbuhkan pada medium potato dextrose agar (PDA) yang dicampur dengan minyak nilam (A dan B) dengan konsentrasi 10, 5, 2.5, 1.25, dan 0.625\%. Sebagai kontrol negatif (Kn), $C$. capsici ditumbuhkan pada medium PDA dan kontrol positif (Kp) pada medium PDA yang dicampur fungisida mankozeb. Hasil uji menunjukkan minyak nilam A efektif secara nyata menekan pertumbuhan C. capsici dibandingkan dengan minyak nilam B pada 10 hari setelah panen, yaitu mencapai $91.15 \%$ pada setiap konsentrasi, kecuali pada konsentrasi $0.625 \%$ kemampuan penghambatan sebesar $85.92 \%$. Minyak nilam A diuji secara in vivo dengan perlakuan preventif, kuratif, dan induksi resisten. Hasil uji menunjukkan masa inkubasi pada uji kuratif ialah 8 hari setelah inokulasi (HSI), sedangkan pada uji preventif dan induksi resisten ialah 5 HSI, sedangkan intensitas serangan C. capsici pada 10 HSI pada uji kuratif $4.80 \%$, preventif $23.20 \%$, dan induksi resisten $29.60 \%$. Intensitas serangan pada kontrol positif (Kp) 29.60\% dan kontrol negatif (Kn) 68.80\%.
\end{abstract}

Kata kunci: Colletotrichum capsici, induksi resisten, patchouli alkohol, uji in vitro, uji in vivo

\begin{abstract}
Anthracnose caused by $C$. capsici is the most important factor causing low yield on chili in Indonesia. A research was conducted to examine to examine the potential of patchouli oil in suppressing anthracnose disease development on chili. In vitro test was conducted by growing $C$. capsici on potato dextrose agar (PDA) medium that has been added with different concentration of patchouli oil, i.e. 10, $5,2.5,1.25$ and $0.625 \%$. Negative controls treatment $(\mathrm{Kn})$ was conducted by growing C. capsici on PDA without patchouli oil, whereas positive controls $(\mathrm{Kp})$ was conducted by growing C. capsici on PDA containing mancozeb fungicide. Patchouli oil -A significantly suppressed the growth of C. capsici compared to patchouli oil-B on 10 days after harvest, i.e. $91.15 \%$ suppression for all concentration level except for $0.625 \%$ which caused $85.92 \%$ suppression. Further examination using patchouli oil-A showed that incubation period on curative test was 8 days after inoculation (DAI) whereas on preventive and induced resistance test were 5 DAI. Disease severity at 10 DAI reached $4.8 \%, 23.20 \%$, and $29.60 \%$ on curative, preventive, and induced resistance tests, respectively. Disease severity was $29.60 \%$ and $68.80 \%$ on positive control and negative control, respectively.
\end{abstract}

Key words: Colletotrichum capsici, induced resistance, in vivo test, in vitro test, patchouli alcohol

*Alamat penulis korespondensi: Departemen Proteksi Tanaman, Fakultas Pertanian, Institut Pertanian Bogor, Kampus Darmaga, Jalan Kamper, Bogor 16680

Tel: 0251-8629364, Faks: 0251-8629362,Surel: bonny_soekarno@yahoo.com 


\section{PENDAHULUAN}

Cabai (Capsicum annuum) merupakan komoditas sayuran yang memiliki nilai komersial tinggi sehingga mendorong petani untuk membudidayakannya. Produktivitas cabai dengan luas panen sebesar 121063 ribu ha di Indonesia tahun 2011 ialah 7.34 ton $\mathrm{ha}^{-1}$ (BPS 2012). Upaya pengendalian antraknosa sampai saat ini masih banyak menggunakan fungisida berbahan aktif benomil, triabendazol, kaptan, klorotalonil, dan kuintozen. Penggunaan fungisida tersebut menyebabkan resistensi terhadap beberapa jenis patogen tanaman serta residu pestisida di atas batas aman buah cabai. Dengan demikian, pengendalian alternatif yang lebih efektif dan aman bagi konsumen serta lingkungan perlu dikembangkan.

Minyak nilam banyak digunakan dalam bidang industri wewangian dan kosmetik karena memiliki sifat sukar menguap dibandingkan dengan minyak atsiri lainnya, sukar tercuci, dapat larut dalam alcohol, dan dapat dicampur dengan minyak eteris lainnya. Oleh karena itu, minyak nilam dipakai sebagai fiksatif (pengikat bau/aroma) untuk industri parfum, kosmetik, industri makanan (untuk penambah rasa), pembuatan pestisida, kebutuhan farmasi (obat antiradang, anticendawan, antiseptik, antijerawat, antiinflamasi, antidepresi, antiflogistik, serta dekongestan), dan sebagai aromaterapi (Sukamto 2009).

Minyak nilam mengandung komponen seskuiterpena gugus fungsional di antaranya patchouli alcohol, kariofilen oksida, aristolone, nookatone, $\beta$-vetivone, $\alpha$-vetivone, dan corymbolone. Patchouli alcohol merupakan komponen utama penyusun minyak nilam dan digunakan sebagai indikator kualitas minyak nilam dan merupakan senyawa seskuiterpena trisiklik yang larut dalam alcohol, eter atau pelarut organik lain. Eugenol termasuk dalam komponen oxygenated monoterpene yang merupakan suatu senyawa fenol yang bersifat anticendawan (Purwati 2011).

Penelitian ini dilakukan untuk menguji potensi minyak nilam untuk menghambat pertumbuhan Colletotrichum capsici, penyebab penyakit antraknosa pada buah cabai dan menentukan potensi fungisida nabati dalam usaha mengendalikan penyakit antraknosa pada buah cabai.

\section{BAHAN DAN METODE}

Isolat $C$. capsici yang digunakan berasal dari buah cabai yang terserang penyakit antraknosa di pertanaman cabai Kampung Gede, Desa Gunung Bunder II, Kabupaten Bogor. Patogen $C$. capsici diisolasi menggunakan medium potato dextrose agar (PDA) dan isolat murninya diuji patogenisitasnya melalui postulat Koch. Hasil isolasi disimpan sebagai biakan koleksi untuk penelitian lanjut. Dua jenis minyak nilam yang diuji ialah minyak nilam dari pasar (A) dan lembaga penelitian (B). Kandungan patchouli alcohol dan eugenolnya dianalisis masing-masing menggunakan uji gas kromatologi dan cassia di Balai Penelitian Tanaman Rempah dan Obat.

\section{Uji in Vitro}

Isolat murni $C$. capsici yang berumur 10 hari berdiameter $7 \mathrm{~mm}$ ditumbuhkan pada medium PDA yang telah dicampur dengan tween $80 \%$ dan perlakuan minyak nilam. Uji minyak nilam sebagai pengendalian penyakit antraknosa dilaksanakan menggunakan dua jenis minyak nilam (A dan B), masingmasing dengan konsentrasi 10, 5, 2.5, 1.25, dan $0.625 \%$. Kontrol positif (Kp) ialah isolat yang ditumbuhkan pada medium PDA yang telah dicampur fungisida mankozeb dengan konsentrasi $0.02 \%(\mathrm{v} / \mathrm{v})$, dan kontrol negatif (Kn) ialah isolat yang ditumbuhkan pada medium PDA tanpa perlakuan minyak nilam. Setiap perlakuan diulang 10 kali.

Pengamatan dilakukan setiap hari dengan mengukur pertumbuhan diameter koloni $C$. capsici sampai pertumbuhan koloni C. capsici pada kontrol menutup seluruh permukaan medium tumbuh. Keefektifan minyak nilam menekan pertumbuhan koloni C. capsici dihitung dengan rumus:

Daya hambat $=\frac{\mathrm{DK}-\mathrm{DP}}{\mathrm{DK}} \times 100 \%$, dengan

DK, diameter koloni C. capsici pada kontrol 
negatif (mm); DP, diameter koloni C. capsici pada perlakuan $(\mathrm{mm})$.

\section{Uji in Vivo}

Uji in vivo dilaksanakan mengggunakan konsentrasi efektif yang dihasilkan dari uji in vitro. Pada uji ini, buah cabai yang diperoleh dari lahan pertanaman cabai, dicuci dengan air bersih, kemudian ditiriskan dan dikeringanginkan. Sterilisasi permukaan buah cabai dilakukan dengan merendamnya di alcohol $70 \%$ selama 3 menit, kemudian dikeringanginkan. Buah cabai dicuci kembali dengan akuades steril dan dikeringanginkan di atas meja pada kertas saring.

Aplikasi minyak nilam terpilih pada buah cabai dilakukan secara preventif, kuratif, dan uji induksi resistensi. Setiap perlakuan diulang 5 kali dan setiap ulangan terdiri atas 5 buah cabai. Sebagai kontrol positif (Kp), buah cabai dicelupkan ke dalam fungisida mankozeb dengan konsentrasi rekomendasi dan sebagai kontrol negatif (Kn), buah cabai dicelupkan ke dalam akuades steril.

Uji preventif dilakukan dengan mencelupkan buah cabai pada minyak nilam dengan konsentrasi terpilih yang telah dicampur dengan akuades steril dan tween $80 \%$ dengan konsentrasi $0.02 \%(\mathrm{v} / \mathrm{v})$ selama 30 detik, kemudian ditiriskan dan dikeringanginkan. Setelah itu, buah cabai diletakkan pada nampan yang dialasi dengan kertas lembap dan diinkubasi selama 48 jam pada suhu dan kelembapan ruang. Setelah inkubasi 48 jam, buah cabai diinokulasi dengan suspensi C. capsici konsentrasi $10^{7}$ spora $\mathrm{mL}^{-1}$ dan selanjutnya diinkubasi kembali.

Uji kuratif dilakukan dengan menginkubasi buah cabai yang telah disterilkan permukaannya menggunakan $\mathrm{NaOCl}$ selama 48 jam pada suhu ruang. Selanjutnya buah cabai diinokulasi dengan suspensi $C$. capsici konsentrasi $10^{7}$ spora $\mathrm{mL}^{-1}$ dan diinkubasi kembali sampai muncul gejala pertama pada salah satu buah cabai. Apabila salah satu buah cabai menunjukkan gejala penyakit antraknosa maka aplikasi dilanjutkan dengan mencelupkan buah cabai ke minyak nilam (konsentrasi terpilih dicampur akuades steril dan tween $80 \%$ ) dengan konsentrasi $0.02 \%$ (v/v) selama 30 detik, kemudian ditiriskan dan dikeringanginkan.

Uji induksi resisten dilakukan dengan mencelupkan buah cabai ke dalam minyak nilam dengan konsentrasi terpilih yang telah dicampur dengan akuades steril dan tween $80 \%$ pada konsentrasi $0.02 \%(\mathrm{v} / \mathrm{v})$ selama 30 detik, kemudian ditiriskan dan dikeringanginkan. Setelah itu, buah cabai diletakkan pada nampan yang dialasi dengan kertas lembap.

Pengamatan dilakukan setiap hari sampai hari ke-10. Peubah yang diamati pada setiap buah cabai dari masing-masing ulangan untuk masing masing perlakuan ialah masa inkubasi sampai munculnya gejala pertama penyakit antraknosa pada buah cabai dan intensitas serangannya.

$$
\begin{aligned}
& \text { Intensitas } \\
& \text { serangan }
\end{aligned}=\frac{\sum(\mathrm{n} \times \mathrm{V})}{\mathrm{Z} \times \mathrm{N}} \times 100 \% \text {, dengan }
$$

$\mathrm{n}$, jumlah buah setiap kelas bercak; $\mathrm{V}$, nilai skor setiap kelas bercak; N, jumlah buah yang diamati; Z, nilai skor kelas luas bercak tertinggi.

\section{Analisis Data}

Data yang diperoleh dari uji in vitro dan in vivo diolah dengan Microsoft Office Excel 2010 dan dianalisis menggunakan program statistical analysis system (SAS) versi 9.1.3. Setiap perlakuan yang berpengaruh nyata diuji lanjut dengan uji Duncan pada taraf $\alpha 0.05$.

\section{HASIL}

Cabai yang terserang antraknosa menunjukkan gejala awal berupa bintikbintik kecil yang berwarna hitam dan sedikit melekuk pada buah cabai. Serangan lebih lanjut mengakibatkan buah mengerut, kering, membusuk, dan terlihat jelas adanya bintikbintik hitam kecil di permukaan buah cabai dengan alur konsentris dan jika diraba akan terasa titik-titik hitam kecil. Pada serangan berat menyebabkan seluruh bagian buah mengerut dan terdapat gejala bintik-bintik hitam dengan pola konsentris.

Minyak nilam A yang digunakan pada penelitian ini mengandung patchouli alcohol $30.62 \%$ dan eugenol $2 \%$, sedangkan minyak 
nilam B kandungannya lebih tinggi (Tabel 1). Hasil uji in vitro juga menunjukkan minyak nilam A lebih efektif menekan pertumbuhan koloni C. capsici dibandingkan dengan minyak nilam kontrol B. Pada kontrol negatif koloni C. capsici menutup hampir seluruh permukaan medium PDA pada hari ke-10. Minyak nilam A mampu menghambat pertumbuhan koloni C. capsici sebesar $86-91 \%$ dan minyak nilam B sebesar 49-86\% (Tabel 2). Berdasarkan pada hasil uji in vitro, aplikasi minyak nilam A dengan konsentrasi $2.5 \%$ selanjutnya digunakan pada uji in vivo.

Aplikasi minyak nilam secara preventif maupun induksi resisten mampu menekan intensitas serangan $C$. capsici secara nyata dibandingkan dengan kontrol negatif, tetapi tidak berbeda nyata dengan kontrol positif, kecuali pada perlakuan kuratif (Tabel 3). Dengan demikian minyak nilam efektif menekan intensitas serangan $C$. capsici sebanding dengan fungisida sintetik. Aplikasi minyak nilam pada buah cabai mempunyai efek

Tabel 1 Hasil analisis kandungan minyak nilam

\begin{tabular}{|c|c|c|c|}
\hline \multirow{2}{*}{$\begin{array}{l}\text { Jenis } \\
\text { pengujian }\end{array}$} & \multirow{2}{*}{ Metode uji } & \multicolumn{2}{|c|}{ Minyak nilam } \\
\hline & & A & $\mathrm{B}$ \\
\hline $\begin{array}{l}\text { Patchouli } \\
\text { alcohol (\%) }\end{array}$ & $\begin{array}{l}\text { Gas } \\
\text { kromatografi }\end{array}$ & 30.62 & 38.21 \\
\hline $\begin{array}{l}\text { Total } \\
\text { eugenol (\%) }\end{array}$ & Cassia & 2 & 6 \\
\hline
\end{tabular}

induksi resistensi. Hal ini sangat bermanfaat untuk meningkatkan ketahanan buah cabai.

Hasil uji in vivo menunjukkan aplikasi minyak nilam secara kuratif memiliki intensitas serangan terendah daripada perlakuan lainnya dengan intensitas serangan penyakit hingga 10 HSI mencapai $4.80 \%$. Aplikasi minyak nilam secara preventif mencapai $23.20 \%$, dan aplikasi minyak nilam secara induksi resisten mencapai 29.60\% (Tabel 4).

\section{PEMBAHASAN}

Penyakit antraknosa dicirikan dengan adanya bercak kehitaman pada permukaan buah kemudian meluas menjadi busuk lunak, pada bagian tengah bercak terdapat kumpulan titik-titik hitam yang merupakan kelompok seta dan konidium cendawan. Wiyono (2007) menyatakan bahwa ekspresi gejala antraknosa cabai tidak hanya menimbulkan busuk pada buah, tetapi juga mati ranting. Cendawan penyebab antraknosa ini berkembang dengan optimum pada suhu $32{ }^{\circ} \mathrm{C}$ dengan kelembapan udara lebih dari $80 \%$ (Hafsah 2007). Koloni C. capsici pada medium PDA berwarna hitam dengan hifa berwarna putih keabu-abuan dan memiliki konidium dengan rata-rata panjang dan lebar bervariasi 23.5-35 $\mu \mathrm{m}$ dan 2.5-3.75 $\mu \mathrm{m}$ (Sangdee et al. 2011).

Minyak nilam merupakan salah satu minyak atsiri yang mengandung senyawa eugenol. Senyawa fenol atau eugenol

Tabel 2 Rataan diameter koloni Colletotrichum capsici dan daya hambat minyak nilam terhadap pertumbuhan koloni $C$. capsici pada medium PDA dengan perlakuan minyak nilam secara in vitro pada10 HSP

\begin{tabular}{lccccc}
\hline Perlakuan & \multicolumn{2}{c}{ Diameter koloni* $(\mathrm{mm})$} & & \multicolumn{2}{c}{ Daya hambat $(\%)$} \\
\cline { 2 - 3 } \cline { 5 - 6 } minyak nilam $(\%)$ & Minyak nilam A & Minyak nilam B & & Minyak nilam A & Minyak nilam B \\
\hline Kontrol negatif $(\mathrm{Kn})$ & $80 \mathrm{a}$ & $80 \mathrm{a}$ & - & - & - \\
Kontrol positif $(\mathrm{Kp})$ & $7 \mathrm{c}$ & $7 \mathrm{f}$ & & $91 \mathrm{a}$ & $91 \mathrm{a}$ \\
10 & $7 \mathrm{c}$ & $13 \mathrm{e}$ & & $91 \mathrm{a}$ & $86 \mathrm{~b}$ \\
5 & $7 \mathrm{c}$ & $12 \mathrm{e}$ & & $91 \mathrm{a}$ & $85 \mathrm{c}$ \\
2.5 & $7 \mathrm{c}$ & $24 \mathrm{~d}$ & & $91 \mathrm{a}$ & $70 \mathrm{~d}$ \\
1.25 & $7 \mathrm{c}$ & $37 \mathrm{c}$ & & $91 \mathrm{a}$ & $54 \mathrm{e}$ \\
0.625 & $11 \mathrm{~b}$ & $41 \mathrm{~b}$ & & $86 \mathrm{~b}$ & $49 \mathrm{f}$ \\
\hline
\end{tabular}

$\mathrm{Kp}$, fungisida mankozeb pada konsentrasi $0.02 \%(\mathrm{v} / \mathrm{v}) ; \mathrm{Kn}$, tanpa perlakuan minyak nilam; HSP, hari setelah perlakuan.

*Angka yang diikuti huruf yang sama menunjukkan tidak berbeda nyata pada taraf uji DMRT $\alpha 5 \%$. 
Tabel 3 Masa inkubasi Colletotricum capsici pada buah cabai pada uji in vivo

\begin{tabular}{lc}
\hline Perlakuan & $\begin{array}{c}\text { Rataan masa } \\
\text { inkubasi* }(\mathrm{HSI})\end{array}$ \\
\hline Kontrol negatif $(\mathrm{Kn})$ & $4.7 \mathrm{~b}$ \\
Kontrol positif $(\mathrm{Kp})$ & $7.9 \mathrm{a}$ \\
Kuratif & \\
Preventif & $4.6 \mathrm{~b}$ \\
Induksi resisten & $6.3 \mathrm{ab}$ \\
\hline
\end{tabular}

Kp, fungisida mankozeb pada konsentrasi $0.02 \%(\mathrm{v} / \mathrm{v})$; $\mathrm{Kn}$, tanpa perlakuan minyak nilam; HSI, hari setelah inokulasi.

*Angka yang diikuti huruf yang sama menunjukkan tidak berbeda nyata pada taraf uji DMRT $\alpha 5 \%$.

Tabel 4 Intensitas serangan Colletotrichum capsici pada buah cabai pada 10 HSI dalam pengujian in vivo

\begin{tabular}{lc}
\hline Perlakuan & $\begin{array}{c}\text { Intensitas serangan* } \\
(\%)\end{array}$ \\
\hline Kontrol negatif $(\mathrm{Kn})$ & $68.80 \mathrm{a}$ \\
Kontrol positif $(\mathrm{Kp})$ & $29.60 \mathrm{~b}$ \\
Preventif & $23.20 \mathrm{~b}$ \\
Kuratif & $4.80 \mathrm{c}$ \\
Induksi resisten & $29.60 \mathrm{~b}$ \\
\hline Kp, fungisida mankozeb pada konsentrasi $0.02 \%(\mathrm{v} / \mathrm{v}) ;$ \\
Kn, tanpa perlakuan minyak nilam. \\
*Angka yang diikuti huruf yang sama menunjukkan \\
tidak berbeda nyata pada taraf uji DMRT $\alpha 5 \%$.
\end{tabular}

yang berasal dari tumbuhan mempunyai sifat sebagai anticendawan. Lebih lanjut Febriyati (2010) melaporkan bahwa senyawa kariofilen, pachouli alcohol, dan fenol mampu menghambat pertumbuhan bakteri mutan Staphylococcus epidermis dan Streptococcus melalui degradasi dinding sel. Senyawasenyawa tersebut merupakan bagian dari komponen penyusun minyak nilam.

Pada aplikasi minyak nilam A dengan konsentrasi $2.5 \%$ pada buah cabai secara kuratif lebih efektif menghambat serangan C. capsici pada buah cabai. Hal ini diduga bahwa aktivitas dari senyawa-senyawa yang terkandung pada minyak nilam yang diaplikasikan pada buah cabai mampu menghambat pertumbuhan dan perkembangan C. capsici yang gejalanya baru muncul.

Berdasarkan hasil percobaanin vitro dan in vivo, minyak nilam efektif menekan pertumbuhan C. capsici dan sebanding dengan fungisida sintetik. Aplikasi minyak nilam A pada konsentrasi $2.5 \%$ pada uji in vivo mampu menekan tingkat serangan $C$. capsici pada buah cabai serta dapat memperpanjang masa simpan buah cabai.

\section{DAFTAR PUSTAKA}

[BPS] Badan Pusat Statistik. 2012. Komoditas Indonesia: produktivitas cabai nasional naik tahun 2011. http://komoditasindonesia. com/2012/08/bps-produktivitas-cabai nasional-naik-1012.[diakses 24 Mar 2013].

Febriyati. 2010. Analisis komponen kimia fraksi minyak atsiri daun sirih (Piper betle Linn.) dan uji aktivitas antibakteri terhadap beberapa jenis bakteri gram positif [skripsi]. Jakarta (ID): Universitas Islam Negeri Syarif Hidayatullah

Hafsah S. 2007. Penapisan genotipe dan analisis genetik ketahanan papaya terhadap penyakit antraknosa di Tajur dan Gunung Geulis Bogor [disertasi]. Bogor (ID): Institut Pertanian Bogor.

Purwati Y. 2011. Komposisi aroma minyak nilam komersial dari beberapa daerah di Indonesia [skripsi]. Bogor (ID): Institut Pertanian Bogor.

Sukamto. 2009. Prospek tanaman nilam penghasil minyak atsiri; pengembangannya melalui sistim pola tanam. J Perkembangan Teknol TRO. 21(2):48-55.

Sangdee A, Sachan S, Khankhum S. 2011. Morphological, pathological and molecular variability of Colletotrichum capsici causing anthracnose of chilli in the North-east of Thailand. Afr J Microbiol Res. 5(25):4368-4372. DOI:10.5897/ AJMR11.476. DOI: http://dx.doi.org/10. 5897/AJMR11.476.

Wiyono S. 2007. Perubahan iklim dan ledakan hama dan penyakit tanaman. Di dalam: Seminar Sehari tentang Keanekaragaman Hayati di Tengah Perubahan Iklim: Tantangan Masa Depan Indonesia; 2007 Jun 28; Jakarta. Bogor (ID): Institut Pertanian Bogor. 